\title{
PLANT PROTECTION GUIDES FOR ORGANIC ARABLE AND VEGETABLE CROPS - A GROWER'S RESOURCE
}

\author{
D.A.J. TEULON ${ }^{1}$, P.J. CAMERON ${ }^{2}$, G.W. BOURDÔT ${ }^{3}$, D.CURTIN ${ }^{1}$ \\ and M. RALSTON ${ }^{4}$
}

\author{
${ }^{1}$ Crop \& Food Research, Private Bag 4704, Christchurch, New Zealand \\ ${ }^{2} 20$ Westminster Road, Auckland, New Zealand \\ ${ }^{3}$ AgResearch Ltd, PO Box 60, Lincoln 8152, New Zealand \\ ${ }^{4}$ Backtrack, RD 12, Rakaia, New Zealand
}

Corresponding author: teulond@crop.cri.nz

\begin{abstract}
A New Zealand guide for pest, disease and weed management in organic arable and vegetable crops was developed. This guide is a resource for current organic growers and their consultants, as well as those contemplating converting to organics. It includes information collected from a wide range of sources within New Zealand and overseas. The guide has three parts: (I) a general section on the principles of soil, pest and disease and weed management in organic systems, (II) an arable section covering barley, borage, clover seed, grass seed, lentils, linseed, maize and wheat, and (III) a vegetable section covering asparagus, brassicas, capsicum, carrot, onion, peas, potato, squash and tomato. For each crop there is a summary of the main pests, diseases and weeds to identify the potential risks to organic growing. The options for preventing or managing these risks that are available to organic growers given the cropping operations and control alternatives available to them are then described. This guide aims to fill the current gap between "introductory" and "anecdotal" organic publications with comprehensive documentation of growing operations that have been used successfully in specific crops for organic pest, disease and weed management.
\end{abstract}

\section{THE APPLICATION PROCESS FOR NEW ORGANISMS REGULATED BY THE ENVIRONMENTAL RISK MANAGEMENT AUTHORITY (ERMA), NEW ZEALAND}

\author{
S.A. WHITEMAN and L. HARRISON \\ ERMA New Zealand, PO Box 131, Wellington \\ Corresponding author: sonia.whiteman@ermanz.govt.nz
}

Applications made for biological control agents (non-genetically modified) include importation of a new organism into containment (NOC), for release (NOR) and for conditional release (NOCR). NOCs allow researchers to do initial screening for efficacy and/or host specificity testing with little risk. Following identification of an effective biological control agent, a NOR is made, which if successful, allows the organism to be released into the environment without restrictions. NOCRs were introduced in 2003 and allow the inclusion of controls such as assessment of efficacy. Lack of post-release monitoring has been an issue raised previously by submitters. The decision making process is based on an assessment that weighs the benefits, costs and adverse effects of the application to the environment, human health and safety, Maori culture, society and the economy. Forms and user guides can be accessed from ERMA New Zealand's website. However, prior to completing forms applicants are advised to contact ERMA New Zealand to ensure that the correct type of application is being made on the most recent form. ERMA New Zealand's Maori unit can provide advice on the process of Maori consultation. These preapplication dealings are invaluable in aiding application processing. 